\title{
PEMBENTUKAN BRAND AWARENESS WARUNK INDOMIE UPNORMAL MELALUI FOOD BLOGGER
}

\author{
Geuit Septiani $^{1}$, Suwandi Sumartias ${ }^{2}$, dan Susie Perbawasari ${ }^{3}$ \\ 1,2,3 Universitas Padjadjaran
}

\begin{abstract}
ABSTRAK
Warunk Upnormal merupakan sebuah tempat makan di Kota Bandung yang saat ini menjadi tren anak muda Bandung untuk nongkrong menghabiskan waktu bersama teman sambil bersantap menu-menu yang spesial. Warunk Upnormal juga sebagai warung pertama di Indonesia yang menghadirkan konsep warung indomie dengan kemasan kekinian (Pelopor Warunk Indomie Kekinian). Penelitian ini bertujuan untuk mengetahui kegiatan pembentukan brand awareness Warunk Indomie Up advertorial online normal melalui food blogger di Kota Bandung. Bagaimana peran food blogger dalam menarik perhatian, menciptakan pemahaman konsumen, dan menciptakan ingatan konsumen mengenai Warunk Indomie Upnormal. Metode penelitianyang digunakan dalam penelitian ini adalah deskriptif dengan data kualitatif. Teknik pengumpulan data yang digunakan adalah wawancara terstruktur, observasi partisipasi pasif, dan studi kepustakaan. Hasil penelitian menunjukkan aspek menarik perhatian yaitu dengan menceritakan pengalaman yang jujur, mengutamakan isi konten, menyelipkan meme lucu, dan komentar positif dari pembaca. Aspek menciptakan pemahaman yaitu dengan mencantumkan informasi yang jelas, memberi keterangan pada setiap foto, bahasa yang disesuaikan dengan target pembaca dan menceritakan keunikan Warunk Upnormal. Aspek menciptakan ingatan yaitu dengan penyebaran informasi mulut ke mulut, meng-upload advertorial online dan kuis, menceritakan kepuasan, dan membuat promosi unik dan menarik. Saran sebaiknya ulasan Warunk Upnormal menampilkan foto yang lebih variatif dan inovatif dibandingkan review tempat makan lain, dan dalam membentuk ingatan sebaiknya menu utama indomie yang lebih sering ditampilkan dibandingkan menumenu lain.
\end{abstract}

Kata-kata Kunci: Brand, awareness, upnormal, food blogger, promosi

\section{FORMATION BRAND AWARENESS WARUNK INDOMIE UPNORMAL THROUGH FOOD BLOGGER}

\begin{abstract}
Warunk Upnormal is a place to eat in the city of Bandung which is currently a trend for young people to hang out Bandung spend time with friends while dining menus special. Warunk Upnormal also as the first stall in Indonesia that presents the concept of indomie stalls with contemporary packaging (Pioneers Warunk Indomie The Presence). This study aims to determine the activities of the establishment of brand awareness Warunk Indomie Upnormal through food blogger in Bandung. How to role in attracting attention, creating consumer awareness and creating consumer memory regarding Warunk Indomie Upnormal. The method used in this research is descriptive qualitative data. Data collection techniques used is a structured interview, observation passive participation, and research studies show aspects kepustakaan. The result of attract attention is to share the experience of being honest, prioritize the content, tucking meme funny, and positive comments from the readers. Aspects of creating an understanding that by including clear information, annotate each photo, language tailored to the target audience and communicating the uniqueness Warunk Upnormal. Aspects of creating memories is by word of mouth information dissemination, uploading online advertorial and quizzes, telling satisfaction, and create a unique promotion and menarik.Saransebaiknya reviews Warunk Upnormal displays the images are more varied and innovative than the reviews of other eating places, and in forming memories indomie the main menu should show more frequently than the other menus.
\end{abstract}

Keywords: Brand, awareness, upnormal, food blogger, promotion

Korespondensi: Geuit Septiani, S.I.Kom. Program Studi Hubungan Masyarakat, Fakultas Ilmu Komunikasi, Universitas Padjadjaran, Jl. Raya Bandung-Sumedang Km 21, Jatinangor 45363. Email: geuitsep@gmail. com 


\section{PENDAHULUAN}

Warunk Upnormal merupakan sebuah tempat makan di Kota Bandung yang saat ini menjadi tren anak muda Bandung untuk nongkrong menghabiskan waktu bersama teman sambil bersantap menu-menu yang spesial. Warunk Upnormal juga sebagai warung pertama di Indonesia yang menghadirkan konsep warung indomie dengan kemasan kekinian (Pelopor Warunk Indomie Kekinian).

Dalam satu setengah tahun berjalan Warunk Upnormal telah menjadi warunk indomie terbesar di Kota Bandung dan telah memiliki tiga belas cabang yang tersebar di beberapa wilayah Kota Bandung, bahkan sampai ke luar kota. Namun, dari keberhasilan dan kesuksesan Warunk Upnormal banyak masyarakat yang belum paham tentang produk utama yang dijual di Warunk Upnormal. Warunk Upnormal bahkan terkenal dengan kafe yang terkenal dengan menjual roti bakarnya. Banyak masyarakat yang tidak tahu Warunk Upnormal adalah warung indomie kekinian.

Hasil penelitian terdahulu, M. Fariz Syahbani dan Arry Widodo, promosi melalui food blogger pada media sosial instagram berada dalam kategori baik. Minat beli mahasiswa di Kota Bandung dalam kategori baik. Promosi melaluifoodblogger pada media sosial instagram berpengaruh secara parsial yang terdiri dari context, communication, collaboration dan connection terhadap minat beli mahasiswa di Kota Bandung dan berpengaruh secara simultan terhadap minat beli mahasiswa di Kota Bandung. Dari penelitian ini terlihat bahwa melalui instagram sebagai media promosi yang efektif dapat memberikan penjelasan dan pesan yang disampaikan secara efektif dan efisien karena menampilkan berbagai macam konteks dengan fitur multimedia yang baik

Hal inilah yang mendasari pihak Warunk Upnormal untuk menjadikan food blogger sebagai media dalam membentuk brand awareness kepada masyarakat kota Bandung. Berdasarkan latar belakang tersebut penulis tertarik untuk meneliti Pembentukan Brand awareness Warunk Indomie Upnormal melalui Food blogger di Kota Bandung.
Hal ini menarik untuk diteliti karena food blogger yang tujuan utamanya hanya sekedar hobi me-review seputar dunia kuliner diuntungkan dengan kegiatan undangan makan gratis di Warunk Upnormal. Food blogger yang merupakan bagian eksternal dari luar perusahaan ini ternyata dapat mengkomunikasikan dan memberi informasi mengenai Warunk Indomie Upnormal. Peran yang dilakukan ini merupakan hal yang baru dimana perusahaan dalam membentuk brand awareness selalu mengandalkan dari pihak internal perusahaan sendiri.

Fokus Penelitian yang ingin peneliti angkat adalah "Bagaimana Pembentukan Brand awareness Warunk Indomie Upnormal melalui Food blogger?". Penelitian ini bertujuan untuk mengetahui pembentukan brand awareness Warunk Indomie Upnormal dalam menarik perhatian konsumen melalui food blogger, untuk mengetahui pembentukan brand awareness Warunk Indomie Upnormal dalam menciptakan pemahaman konsumen melalui food blogger, dan untuk mengetahui pembentukan brand awareness Warunk Indomie Upnormal dalam menciptakan ingatan konsumen melalui food blogger.

\section{METODE PENELITIAN}

Metode penelitian yang digunakan peneliti dalam penelitian ini adalah metode deskriptif. Penelitian deskriptif hanya memaparkan situasi atau peristiwa. Titik beratnya pada observasi dan suasana ilmiah (natural setting). Penelitian ini tidak mencari atau menjelaskan hubungan, tidak menguji hipotesis atau membuat prediksi. Peneliti hanya bertindak sebagai pengamat yang membuat kategori perilaku, mengamati, dan mencatat. (Rakhmat, 2012 : 24-25)

Penelitian ini menjabarkan bagaimana fakta-fakta nyata mengenai pembentukan brand awareness Warunk Indomie Upnormal melalui food blogger. Pada penelitia $\mathrm{n}$ ini menurunkan konsep tiga aspek dalam membangun awareness oleh Ronald D. Smith dalam buku Strategic Planning for Public relations.

Teknik sampel yang digunakan dalam penelitian ini adalah purposive sampling 
yang merupakan teknik pengambilan sampel sumber data dengan pertimbangan tertentu. Pertimbangan tertentu ini misalnya orang tersebut yang dianggap paling tahu tentang apa yang kita harapkan atau mungkin dia sebagai penguasa sehingga akan memudahkan peneliti menjelajahi objek/situasi sosial yang diteliti (Sugiyono, 2012: 218).

Purposive sampling yaitu memilih orangorang tertentu karena dianggap berdasarkan penilaian tertentu mewakili statistik, tingkat signifikan, dan prosedur pengujian hipotesis (Rakhmat, 2012: 81). Kriteria umum informan yang akan peneliti teliti ialah mereka yang menguasai atau memahami sesuatu melalui proses enkulturasi, sehingga sesuatu itu bukan sekedar diketahui, tetapi juga dihayatinya. Mereka yang tergolong masih sedang berkecimpung atau terlibat pada kegiatan yang tengah diteliti. Mereka yang mempunyai waktu yang memadai untuk dimintai informasi. Mereka yang tidak cenderung menyampaikan informasi hasil "kemasannya" sendiri. Mereka yang pada mulanya tergolong "cukup asing" dengan peneliti sehingga lebih menggairahkan untuk dijadikan semacam guru atau narasumber (Satori, 2012: 55).

Kriteria khusus informan yang akan peneliti teliti ialah bersedia diwawancarai peneliti dan memiliki waktu yang memadai untuk dimintai informasi. Terlibat langsung dalam me-review Warunk Upnormal. Memliki keterikatan kerja sama dengan pihak Warunk Upnormal. Memiliki karakteristik dan target market yang berbeda dengan food blogger lain. Memahami secara keseluruhan mengenai isi konten review Warunk Upnormal. Menguasai atau memahami dan masih berkecimpung dalam kegiatan food blogger

Teknik pengumpulan data adalah teknik bagaimana data itu bisa ditemukan, digali, dikumpulkan, dan dikategorikan. Menurut (Sugiyono, 2012: 225). teknik pengumpulan data yang dipergunakan dalam penelitian ini yaitu observasi, wawancara, studi kepustakaan. Teknik analisis data yang digunakan dalam penelitian ini adalah reduksi data, penyajian data, dan verifikasi data.

Teknik pemeriksaan yang digunakan adalah dengan triangulasi, yaitu teknik pemeriksaan keabsahan data yangmemanfaatkan sesuatuyang lain diluar data itu untuk keperluan pengecekan atau sebagai pembanding terhadap data itu. (Moleong, 2013: 330). Teknik triangulasi yang digunakan ialah pemeriksaan melalui sumber, yaitu kepada salah satu followers Food blogger Bandung yaitu Mahasiswa Universitas Pendidikan Indonesia, Shinta Puji Heryati.

\section{HASIL DAN PEMBAHASAN}

Brand adalah ide, kata, desain grafis dan suara/bunyi yang mensimbolisasikan produk, jasa, dan perusahaan yang memproduksi produk dan jasa tersebut. Semua aspek tangible ini menerbitkan asosiasi khusus dalam benak konsumen, misalnya tentang kualitas produk, makna simbolis yang dikandung dan pengalaman emosional dan psikologis yang dialami oleh konsumen dalam persentuhannya dengan brand tersebut (Dewi, 2009 : 4).

Menurut UU Merek No.15 Tahun 2001 pasal 1 ayat 1, merek adalah "tanda yang berupa gambar, nama, kata, huruf-huruf, angka-angka, susunan warna, atau kombinasi dari unsurunsur tersebut yang memiliki daya pembeda dan digunakan dalam kegiatan perdagangan barang atau jasa".

Brand awareness yaitu kemampuan konsumen untuk mengenali atau mengingat bahwa sebuah merek merupakan anggota dari kategori produk tertentu. Brand awareness (kesadaran merek) menggambarkan keberadaan brand dalam benak konsumen, yang dapat menjadi penentu dalam beberapa kategori. Brand yang kuat dicerminkan oleh brand awareness yang tinggi dan asosiasi merek (brand association) yang kuat dan positif (Tjiptono, 2005: 40).

Kesadaran merek (brand awareness) menggambarkan kesanggupan seorang calon pembeli untuk mengenali, mengingat kembali suatu merek sebagai bagian dari suatu kategori produk tertentu. Pada umumnya konsumen cenderung membeli produk dengan merek yang sudah dikenalnya atas dasar pertimbangan tertentu seperti kenyamanan, keamanan, menghindarkan risiko karena sudah pernah 
mengkonsumsi. Kesadaran merek merupakan key of brand asset atau kunci pembuka untuk masuk ke elemen lainnya. Jadi, jika kesadaran itu sangat rendah maka hampir dipastikan bahwa ekuitas mereknya juga rendah. Adapun menurut Ronal D, Smith (1948) objective awareness terdiri dari 3 yaitu: attention: perhatian/ daya tarik, comprehension: pemahaman, retention: ingatan.

Dalam penelitian yang dilakukan oleh (Wicaksono \& Seminari, 2016) Mengemukakan bahwa strategi promosi yang yang memiliki pengaruh yang besar terhadap brand awareness adalah iklan dan word of mouth berbeda artinya iklan dan word of mouth memiliki pengaruh signifikan terhadap brand awareness.

Weblog merupakan kependekan dari $\mathrm{Web}$ dan Log. Web adalah halaman Internet atau situs, sedangkan log adalah semacam jurnal, laporan, diari. Jadi, bisa kita simpulkan bahwa pengertian dari Weblog atau blog adalah sebuah Website, halaman internet yang memuat tentang laporan. Isi dari blog ini nantinya yang akan membedakan dengan sebuah site atau Website. (Madcoms, 2008: 4).

Pertama ketika mendengar kata blogger mungkin kita akan langsung menuju pada istilah pengguna blog, memang layanan yang satu ini memanfaatkan istilah tersebut untuk memudahkan pengguna untuk mengingat. Blogger adalah produk dari Pyra Lab yang kemudian diakuisisi oleh Google. Hingga sekarang Blogger bisa dikatakan sebagai penyedia layanan blog tersukses dan teramai dalam urusan menggaet netter. (Madcoms, 2008: 11). 2015):

Menurut Octavianti dalam (Herdana,

"Semakin banyaknya pelaku bisnis yang bergerak dalam bidang usaha yang sejenis serta memproduksi dengan menawarkan berbagai macam produk/jasa, membuat masyarakat sulit menentukan pilihan produk yang sesuai dengan kebutuhan mereka. Salah satu hal yang dapat dilakukan oleh para pelaku bisnis untuk membedakan produknya dengan produk kompetitor yaitu melalui merek (brand)".

Food blogger adalah sebutan bagi mereka yang mengisi blognya dengan ulasan tentang makanan atau tempat makan, mulai jajanan warung, kafe, hingga restoran yang tersedia di hotel. Menjadi food blogger, artinya mereka harus bisa memberikan panduan atau rekomendasi terpercaya tentang menu makanan atau tempat makanan yang layak dicoba. Artinya, mereka harus paham seperti apa makanan yang enak atau tempat makan serta tempat nongkrong yang nyaman.

Pembentukan brand awareness Warunk Indomie Upnormal dalam menarik perhatian konsumen melaluifood blogger. Menyampaikan perbedaan dan keunikan tersendiri yang dimiliki oleh setiap Food blogger. Food blogger Dunia Kuliner Bandung yang merupakan food blogger terbesar dan pertama di Bandung memiliki target pembaca semua usia dan telah memiliki ratusan ribu followers. Food blogger Bully Your Belly yang menggunakan bahasa Inggris karena ingin dianggap premium pada setiap hasil ulasannya dan memiliki target kalangan menengah ke atas. Food blogger Makan Pake Receh yang selalu menyisipkan meme lucu di setiap ulasan dan juga beberapa selipan kata jokes dengan target pembaca kalangan pelajar dan mahasiswa yang memiliki uang saku terbatas.

Food blogger menceritakan pengalaman baik mengenai keunikan dan perbedaan Warunk Upnormal dengan warung indomie lain seperti pelayanan yang ramah, bisa untuk nongkrong lama dan memainkan permainan, harganya murah namun suasana seperti layaknya kafe dengan beberapa fasilitas yang dimiliki dan juga menu yang disajikan sangat unik tidak terdapat di beberapa kafe lain.

Menurut Sanjaya (2009: 18) pengalaman dapat berupa elemen "think" dan "feel". Unsur "think" tercipta ketika food blogger berhubungan dengan segala aktivitas marketing milik organisasi. Dalam hal ini apa yang dipikirkan atau dipersepsikan food blogger ketika melihat komunikasi marketing yang dilakukan organisasi.

Food blogger dalam menarik perhatian pembaca menceritakan keunikan suasana makan di Warunk Upnormal dengan warung indomie lain. Dekorasi yang terdapat di Warunk Upnormal dibuat senyaman mungkin dengan 
pajangan dinding berupa quote-quote unik yang bertuliskan; Jika pindah meja harap infokan ke waiter, jika pindah hati harap infokan ke mantan, Musholla sholat dulu biar ringan jodoh. Selain itu keunikan lain terdapat dalam password wifi seperti: jodohkupastidisini, jodohgakankemana.

"Kalo di blog pasti pertama over view-nya ajasi antara yang headline biasa antara makanan terbaiknya atau view terbaik terus kita jalan ke interiornya dulu biar orang bisa ngerasain kaya apasih kalo kita ngunjungin Warunk Upnormal yang cabang Cihampelas kebetulan ini situasinya kaya apa sih. Jadi rame enggaknya juga keliatan sih sebenernya langsung. Terus abis itu biasanya kita ke menu kalo ada kadangkadang suka ga ada kan suka ditempel. Menu kita biar tau sih makanan disini tuh berapa aja sih jadi kan kalo di instagram kaya cuma pricerange segini sampe segini." (Sumali, 2016).

Food blogger dalam menarik perhatian baik di media instagram dan blog dalam menulis review mengenai Warunk Upnormal menyelipkan caption tambahan untuk menarik perhatian. Contohnya: Perkenalan pertama begitu mengesankan selanjutnya, terserah Anda. Hujan dan galau ga harus diobatin sama mie instan aja kan?. Bye rumput tetangga! kamu kalah ijo sama yang ini!. yang manis di foto, ternyata manis juga di lidah. daripada dibilang sadis manis, lebih pas dibilang Sadis Miris. Mungkin yang masak kebelet nikah. Agar menarik perhatian dalam review Warunk Upnormal yaitu dengan memasukan foto-foto.

"Foto yang di post itu kadang kita suka pilih juga, kaya kita kan pengen berusaha untuk menaikkan suatu tempat makan, Jadi kita selalu milih menunya yang memang unik di tempat lain mungkin gabisa niru atau memang gada di tempat lain. Makanya kita pilih beberapa menunya. Biasanya ngobrol dulu sama owner menurut kita oke nya gini dan owner biasanya ngikutin kita sih karena kan kita tau yang mau dibahasnya." (Victor, 2016).

Menurut Sanjaya (2009: 152) apabila terdapat produk yang bisa ditampilkan seperti penampilan gambar/foto, secara rutin dapat menarik perhatian pembaca untuk melihat konten di dalamnya. Apabila disertai dengan informasi yang jelas dan menarik, akan tercipta suatu pembicaraan yang akan mengarah pada kesepakatan tertentu.

Adapun salah satu food blogger Bandung yaitu Makan Pake Receh selalu menyelipkan meme dalam setiap mengunggah foto makanan yang akan diulas. Seperti contohnya foto menu Alpukat Greentea yang diberi meme "Alpukat aja dikasih green tea laku, apalagi kamu mblo" dan juga foto mie goreng diberi sisipan berupa "mie instan = Makanan yang langsung jadi dalam 3 menit, ga berbulan-bulan kaya PDKT kamu sama si dia."

Komentar-komentar positif yang disampaikan pembaca sehingga mendorong pembaca lain untuk memberikan komentar. Menurut Luttrell (1975:219) aktivitas blog commenting mempunyai pengaruh dalam beberapa hal yaitu: engagement dan percakapan, pengaruh (influence), opini dan advokasi, dampak dan nilai, kesadaran merek (brand awareness) dan link back.

Pembentukan brand awareness Warunk Indomie Upnormal dalam menciptakan pemahaman konsumen melalui food blogger. Mencantumkan informasi mengenai kejelasan harga, lokasi, dan alamat Warunk Upnormal yang diberi rate/nilai oleh food blogger dapat dikaitkan sebagai salah satu pelaksanaan strategi public relations dalam berkomunikasi yang diutarakan oleh Ruslan (2006: 122) yaitu mengenai clarity (kejelasan) yang berarti pesan harus disusun dengan kata-kata yang jelas, mudah dimengerti, serta memiliki pemahaman yang sama antara komunikator dan komunikan dalam hal maksud, tema dan tujuan semua pihak.

"Kita pasti cantumin itu karena mayoritas orang Bandung pasti liat harga dulu sebelum liat makanannya apa gitu, jadi pasti buat kita itu harga penting karena kita berdua juga termasuk orang yang liat kafe kadang-kadang aduh mahal nih ya takut tapi kalo liat di food blogger kan bisa tau oh ternyata kafe ini the range harganya dari segini sampe segini jadi gausah takut masuk ke dalem karena food blogger-nya nulis seperti itu. Memang kita itu pasti 
ngasih info harga tempat, jam buka, alamat, kalo bisa reservasi bisa telepon ke mana." (Victor, 2016).

Setiap foto yang dicantumkan tentunya selalu diberi keterangan dan penjelasan cukup rinci. Menurut Luttrell (1975: 131) berbagi foto dengan orang-orang di media sosial, sementara juga mendorong mereka untuk berbagi, komentar, dan berinteraksi dengan perusahaan. Instagram memungkinkan perusahaan untuk menciptakan komunitas, gambar berbagi, membangun kepercayaan, dan mengembangkan keaslian dengan konsumen seperti semua platform media sosial lain yang telah dibahas.

Menyesuaikan target pembaca mereka dan juga target market Warunk Upnormal yang merupakan mahasiswa dan pelajar. Penyesuaian target pembaca food blogger dan Warunk Upnormal terdapat pada cara untuk mengevaluasi awareness (kesadaran) menurut Smith (1948: 249) dengan aspek comprehension (pemahaman) yaitu dari readability measures (tindakan membaca) yang merupakan seberapa mudahnya pesan tersebut untuk dipahami.

Untuk mempermudah pembaca atau konsumen dalam mencari review mengenai Warunk Upnormal, food blogger mempermudah pencarian dengan menambahkan hashtags di instagram dan juga berupa kategori produk dan kumpulan kata kunci seperti indomie, makan enak, kafe kekinian, warung gaul, dan lain-lain.

"Kalo kita upload di instagram pasti selalu masukin hashtag yang berkaitan dengan tempat makan itu, kaya Warunk Upnormal kan side dish-nya indomie kita tambahin kaya \#warungindomie \#warunggaul \#foodporn \#indomiegokil seperti itu, nah kalo di blog dia itu masuk di kategori kayak ke kafe, tempat nongkrong, cheap eating dan lain-lain. Itu digunakan ya supaya memudahkan pencarian orang-orang aja misalkan pengen makan sesuatu yang baru dengan tempat nongkrong enak ya keluarnya Warunk Upnormal.” (Ayudiana, 2016).

Pembentukan brand awareness Warunk Indomie Upnormal dalam menciptakan ingatan melalui food blogger. Review Warunk Upnormal yang diulas food blogger tentunya akan menyebabkan penyebaran berupa informasi mulut ke mulut (word of mouth) ke sesama pengguna media sosial. Informasi dari mulut ke mulut yang dilakukan oleh food blogger dapat dikaitkan dengan pernyataan menurut Kotler (2005: 615) yang menjelaskan Word of mouth Communication adalah "Komunikasi pribadi tentang sebuah produk antara pembeli sasaran dan para tetangga, teman, anggota keluarga, serta rekannya".

Dalam meningkatkan ingatan mengenai Warunk Upnormal, tentunya food blogger menceritakan tentang kepuasan mereka ketika datang dan makan di Warunk Upnormal. Kepuasan, kualitas pelayanan dan beberapa poin yang disampaikan dalam review Warunk Upnormal, termasuk ke dalam kelompok variabel yang mempengaruhi costumer retention yaitu costumer perception (persepsi konsumen).

"Kalo kepuasan sih memang mereka tuh hebatnya bisa bikin panggilan kalo di Upnormal kan suka dipanggilnya bro/ sis itukan sesuatu yang unik dibandingin kafe lain yang biasa manggil mas dan mba aja terus kalo nanya password wifi pas pertamanya sih suka nanya itu juga kadangkadang unik kaya "jodohkupastidisini". Desain interiornya pun bagus engga gelap tapi ga terlalu terang juga terus makanannya enak harganya juga oke lah gitu masih masuk, makanannya enak sih itu." (Victor, 2016).

Memposting advertorial yang diberikan pihak Warunk Upnormal kepada komunitas bandung foodies untuk mem-post di akun media sosial mereka masing-masing dengan waktu dan jam-jam yang telah ditentukan. Pengertian Advertorial (Iklan sponsor) adalah bagian dari bauran promosi (promotion mix) dan bauran dari promosi adalah bagian dari bauran pemasaran (marketing mix).

"Itu pasti ada seperti buka cabang baru, promosi makan gratis, produk baru, cuma pasti kita emang tergantung dari pihak upnormalnya, kadang-kadang mereka suka order iklan kaya advertising jadi kita bantu buzz karena zaman sekarang kan yaitu 
banyak orang liatnya food blogger. Jadi semuanya kalo saya liat upnormal tuh kaya gitu banyak nge-buzz di media sosial." (Victor, 2016)

Adapun promosi yang dibuat sendiri oleh para food blogger dengan sekreatif dan semenarik mungkin dan juga dengan hasil persetujuan pihak Warunk Upnormal. Salah satu promosi yang dilakukan food blogger Makan Pake Receh yaitu pada saat bertepatan dengan hari valentine mereka membagi-bagikan 100 voucher gratis makan di Warunk Upnormal dengan beberapa syarat dan ketentuan yang berlaku.

Promosi yang baik dapat menciptakan brand awereness dan sakan menciptakan kestiaan konsumen pada suatu merek. Brand loyalty (kesetiaan merek) adalah konsumen secara konsisten melakukan pembelian pada merek yang sama. Kesetiaan pada sebuah merek timbul karena konsumen merasa merek tersebut memberikan manfaat dan kualitas dengan harga yang sesuai (Nugroho \& Rochmah, 2013).

\section{SIMPULAN}

Pembentukan brand awareness Warunk Indomie Upnormal dalam menarik perhatian konsumen melalui food blogger telah dilakukan dengan baik yaitu dengan cara memperhatikan angle dan kejelasan detail foto menceritakan pengalaman baik, menyelipkan meme lucu di setiap tampilan foto dan menyelipkan quote unik agar dapat menarik perhatian pembaca, namun masih terdapat aspek yang belum dilakukan food blogger dalam menarik perhatian yaitu food blogger kurang berinteraksi dengan publik seperti komentar ataupun pertanyaan dari pembaca yang tidak dibalas oleh food blogger. Pembentukan brand awareness Warunk Indomie Upnormal dalam isi informasi yang diberikan cukup lengkap dan dapat mudah dipahami oleh pembaca, karena kejelasan isi konten yang mencantumkan lokasi dengan pemberian gambar peta dan alamat jelas, mencantumkan harga dan juga memberikan rate/nilai tentang suasana dan fasilitas di Warunk Upnormal. Isi konten pun disesuaikan sesuai target pembaca, namun masih terdapat beberapa food blogger yang kurang rinci dalam menjelaskan isi informasi. Pembentukan brand awareness Warunk Indomie Upnormal dalam menciptakan ingatan yaitu dengan mempost advertorial, membuat promosi unik , dan menceritakan kepuasan mereka makan di Warunk Upnormal namun dirasa kurang yaitu tidak melakukan pengulangan kata untuk membentuk ingatan pembaca terhadap Warunk Upnormal. Dalam meng-upload kuis dan promosi pun tidak dilakukan secara teratur. Untuk melengkapi hasil penelitian ini, peneliti memberikan beberapa saran, yaitu: Food blogger seharusnya membangun interaksi dengan para pembaca dan followers-nya yaitu dengan membalas komentar-komentar dan pertanyaan yang dilontarkan oleh pembaca, sehingga engagement dengan konsumen terjalin dengan baik. Pihak Warunk Upnormal seharusnya melakukan evaluasi kepada setiap review yang diunggah oleh para food blogger. Dalam me-review Warunk Upnormal ulasan yang ditampilkan masih satu level dengan review tempat makan lain sehingga ketika pembaca melihat kurang fokus dan dirasa kurang variatif dan inovatif seharusnya dibarengi dengan menshare kuis/instagram competition dan informasi diskon agar terlihat lebih menarik dibanding tempat makan lain. Sebaiknya konten mengenai Warunk Upnormal mempunyai jadwal rentang waktu yang cukup sehingga tidak akan tertutup dengan konten review tempat makan lain. Strategi dalam membentuk ingatan berupa kuis dan promosi seharusnya dilakukan terus menerus berkelanjutan tidak hanya sekali dua kali saja. Food blogger dalam membentuk ingatan mengenai Warunk Upnormal sebagai warung indomie kekinian seharusnya memasukkan pengulangan kata spesifik seperti "warung indomie" dalam review-nya.

\section{DAFTAR PUSTAKA}

Ayudiana, D. (4 April, 2016). Personal Interview Dewi, I. J. (2009). Creating and sustaining brand equity. Yogyakarta: Amara Books

Herdana,A. (2015). Analisis pengaruh kesadaran merek (brand awareness) pada produk 
asuransi jiwa prudential life assurance (studi pada passion agency jakarta). Jurnal Riset Bisnis dan Manajemen Vol. 3, 2-12

Kotler, P. (2005). Manajamen pemasaran, jilid 1 dan 2. Jakarta: Kelompok Gramedia

Luttrell, R. (1975). Social media: how to engage, share, and connect. London: Rowman \& Littlefield

Madcoms. (2008). Mahir dalam 7 hari menggunakan blogger. Yogyakarta: Andi

Moleong, L. J. (2013) Metodologi penelitian kualitatif. Bandung: Remaja Rosdakarya

Nugroho, I. S. \& Rochmah, T. N. (2013). Analisis pengaruh brand equity terhadap keputusan masyarakat dalam memilih rumah sakit muhammadiyah surabaya. Jurnal Administrasi Kesehatan Indonesia Volume 1, 147-155

Rakhmat, J. (2012). Metode penelitian komunikasi. Bandung: Remaja Rosdakarya
Ruslan, R. (2006). Manajemen public relations dan media komunnikasi konsep (edisi revisi). Jakarta: Raja Grafindo Persada

Sanjaya, R. (2009). Creative digital marketing. Jakarta: Elex Media Komputindo

Satori, D. (2011). Metode Penelitian Kualitatif. Bandung: Alfabeta

Smith, R. D. (1948). Strategic Planning for Public relations. London: Lawrence Erlbaum Associates

Sugiyono. (2012). Metode penelitian kuantitatif kualitatif dan $r \& d$. Bandung: Alfabeta

Sumali, M. (31 Maret, 2016). Personal Interview Tjiptono, F. (2005). Brand management and strategy. Yogyakarta: Andi

Victor. (30 Maret, 2016). Personal Interview

Wicaksono, M. P. \& Seminari, N. K. (2016). Pengaruh iklan dan word of mouth terhadap brand awareness traveloka. E-Jurnal Manajemen Unud, Vol. 5, 98-127 